\title{
Low hybrid onion seed yields relate to honey bee visits and insecticide use
}

by Rachael F. Long and Lora Morandin

Onion thrips, previously considered of minor importance to hybrid onion seed production in California, vector the newly introduced iris yellow spot virus, a serious pathogen of onions that can cause significant yield losses. Insecticide use to control onion thrips has increased in onion seed fields, coincident with a steep decrease in yields, especially in Colusa County. We examined a number of possible contributing factors and found a strong positive correlation between honey bee activity and onion seed set, indicating that a lack of pollination may be contributing to the reduced yields. In addition, honey bee visits to onion flowers were negatively correlated with the number of insecticides applied per field and field size. Reduced onion seed yields in recent years could be associated with the increase in insecticide use, which may be repelling or killing honey bees, important pollinators of this crop.

The production of hybrid onion seed in 1 California has traditionally exhibited variable and unpredictable yields, but in recent years they have declined markedly (fig. 1). This additional uncertainty around the crop makes it difficult for the industry to contract with growers and maintain inventory for onion seed orders.

Hybrid onion production for a seed crop involves encouraging onion bulbs to flower, via a combination of factors including variety, planting date and temperature. Onion seed is primarily grown in Colusa County and the Imperial Valley on about 2,000 acres, although some production in Colusa County has recently shifted to other regions because of the yield declines. The market for seeds of red, yellow and white onion varieties extends worldwide. The value of the seeds

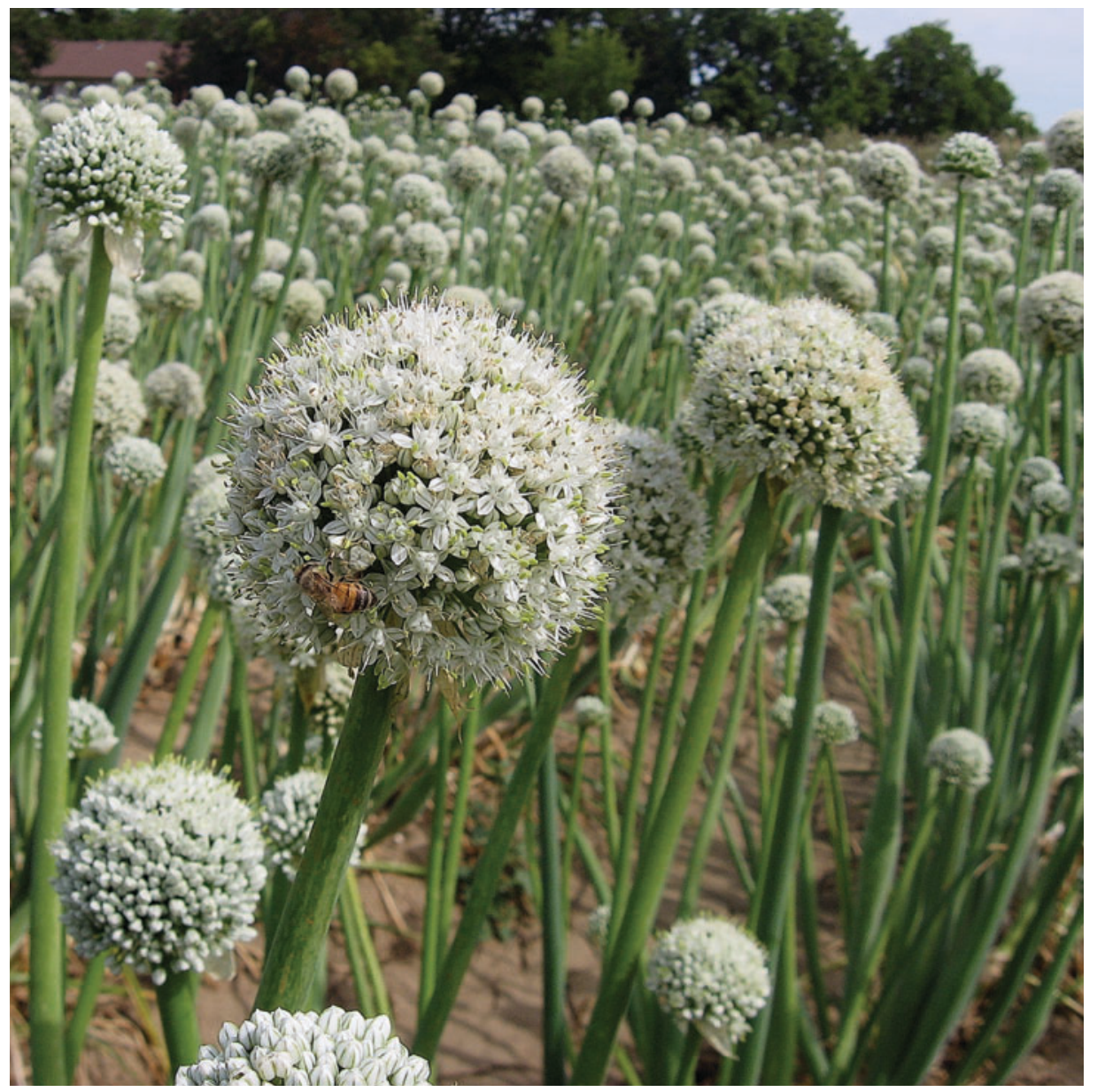

Onion seed yields have declined significantly in recent years in Colusa County, where the crop plays a small but important role in the rural economy. Above, a honey bee visits an onion umbel.

is $\$ 12$ million to growers, according to agricultural commissioner county crop reports, and they generate an additional $\$ 40$ million in subsequent retail sales. While clearly a specialty, small-acreage crop, onion seed production is important to the rural economies in California where onion seed is primarily grown.

The causes of yearly variability in the production of seed onions are unknown. In the absence of any significant changes in landscapes, agronomic practices, acreage or onion seed varieties during the past 10 years that would explain yield variations and the recent dramatic drop-off in yields, we turned our attention to a lack of pollination and seed set. To produce hybrid seed, distinct male (male fertile) and female (male sterile) onion lines are planted in the same field. Honey bee (Apis

\section{The strong positive correlation between honey bee activity and onion seed set indicates that a lack of pollination may be contributing to reduced yields.}

mellifera) hives are brought in to the fields for cross-pollination at a recommended rate of 10 to 12 hives per acre (Voss et al.

Online: http://californiaagriculture.ucanr.org/ landingpage.cfm?article $=$ ca.v065n03p155\&fulltext=yes DOI: 10.3733/ca.v065n03p155 


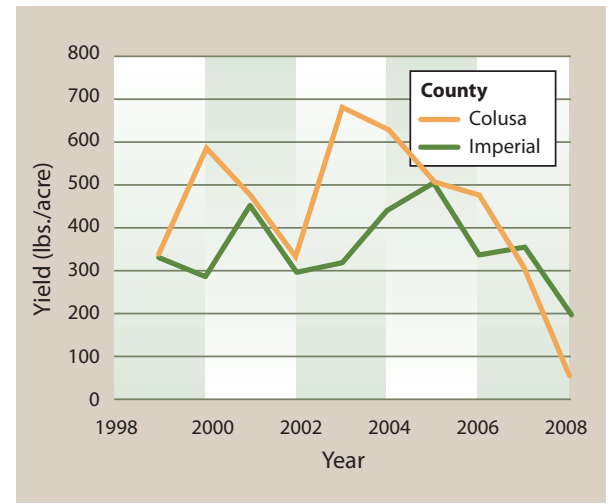

Fig. 1. Hybrid onion seed yields in Colusa and Imperial counties, 1999-2008. Source: Agricultural commissioner county crop reports.

1999). Wild bees also can be important; if they are present and visiting flowers, higher seed set results (Parker 1982).

One cause for poor recent seed harvests may be the increased use of insecticides to control onion thrips (Thrips tabaci), the number used possibly affecting the activity of wild bees and honey bees. Onion thrips were previously of minor importance in onion seed production. However, iris yellow spot virus is a new pathogen for California onions that vectors onion thrips, and it can cause significant onion seed yield losses if left unmanaged (Gent et al. 2004). We examined the activity of honey bees and other insect pollinators in commercial onion seed fields to understand the causus of the yield declines in recent years.

\section{Onion seed fields}

Our research was conducted in May and June 2009 in 13 commercial hybrid onion seed production fields in Yolo and Sacramento counties, which varied in size from 6 to 50 acres. Nine of the study fields were planted with different female cultivars, and nine fields had different male cultivars. Within each field, six monitoring sites were established along two transects at about 10, 200 and 500 feet from the field edges, where honey bee hives were placed, so we could conduct analyses with distance from hives as a factor.

At each of the six sampling sites per field, we observed the numbers and types of insects visiting onion flowers that were potential pollinators of onions. These included honey bees, wild bees (mostly Halictus and Bombus spp.), flies (Syrphidae and other Diptera) and wasps (Hymenoptera). Five-minute observations were made in each of two 1-square-meter quadrats, mostly between 10 a.m. and

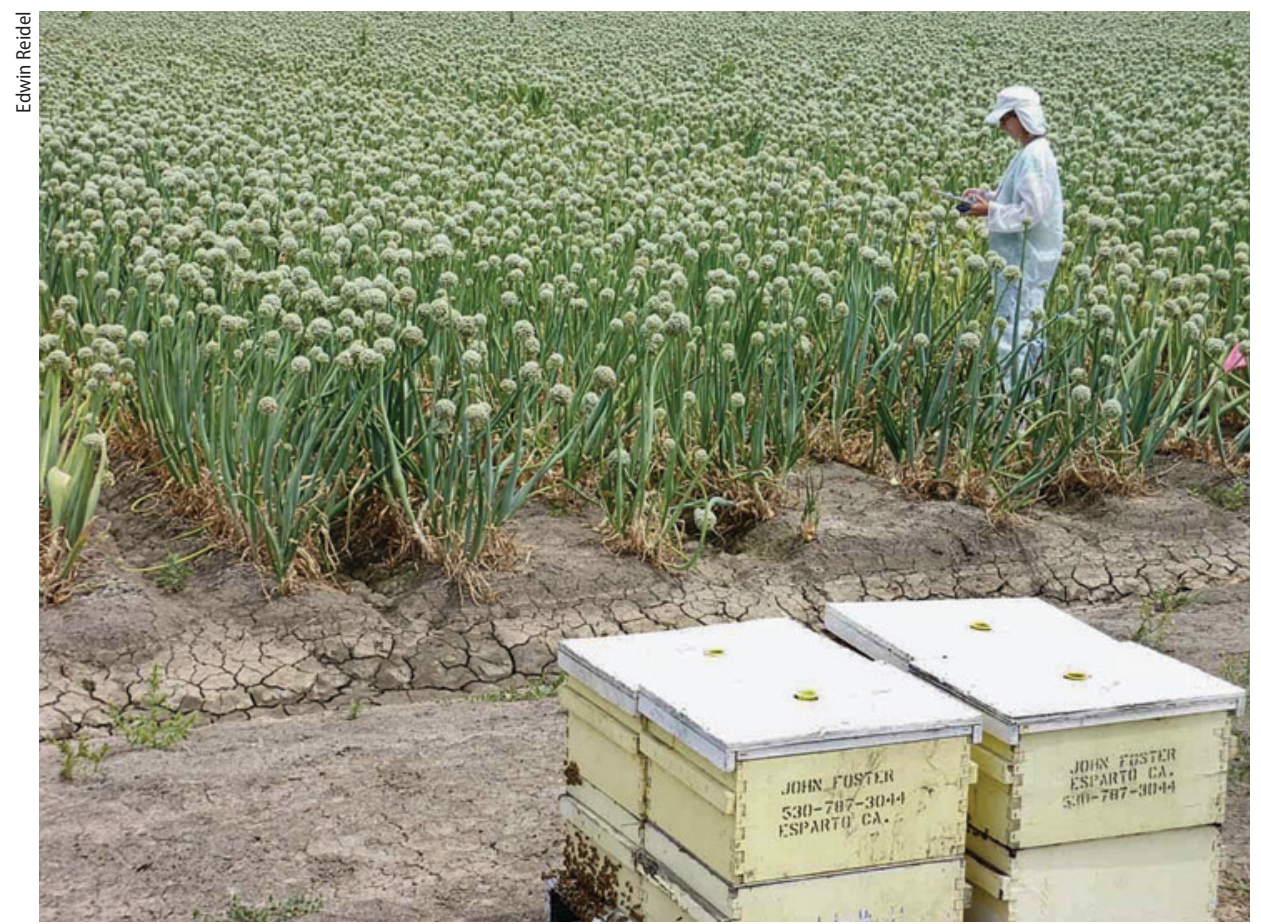

Honey bee hives are brought in to onion fields to pollinate the crop. Above, Yolo County farm advisor Rachael Long conducts observations of onion pollinators.

5 p.m., with one observation in the female row and the other in the male row. These observations were made every 3 or 4 days for a total of 10 minutes per site, or 60 minutes per field. We began our observations of insect activity in each field when the female umbels (flower heads) were at about $5 \%$ flower bloom and ended when the flowers finished blooming and seeds were set, about 21 days later. Weather conditions were recorded during monitoring, and pollinators were observed when temperatures averaged about $75^{\circ} \mathrm{F}$ to $85^{\circ} \mathrm{F}$ $\left(25^{\circ} \mathrm{C}\right.$ to $\left.30^{\circ} \mathrm{C}\right)$.

To assess onion seed yields relative to insect pollinator activity, we collected eight onion umbels at each of the six sites per field, for a total of 48 umbels per field. These were placed individually in labeled paper bags and dried. Seeds were then threshed and counted to obtain average yield data (number of seeds per umbel).

One to two days before nectar collection, plastic bags were placed over four male and four female umbels per field that were approximately the same size and at the same stage of bloom (Silva and Dean 2000). Bagging was done to minimize nectar evaporation and prevent honey bee foraging. Paper bags were placed over the plastic bags to minimize temperature increases. Nectar was collected from each umbel using 10-microliter capillary tubes and dispensed onto a refractometer to measure the percentage of sugar solids.

Ground mapping was done once around each field during midbloom to determine whether other preferred floral resources were available to honey bees, perhaps luring them away from onion flowers. Observers drove a 1-mile radius around each field, mapping out all other crops, particularly noting any crops in which bloom was concurrent with onion bloom. Observers also recorded any significant areas (more than 50 square feet) of natural or weedy vegetation that had plants in bloom.

The insecticides used on our field production sites for thrips control included spinosad, spinetoram, methomyl, cypermethrin, lambda-cyhalothrin and sodium tetraborohydrate decahydrate. The number of insecticides applied per field ranged from one to seven, including 


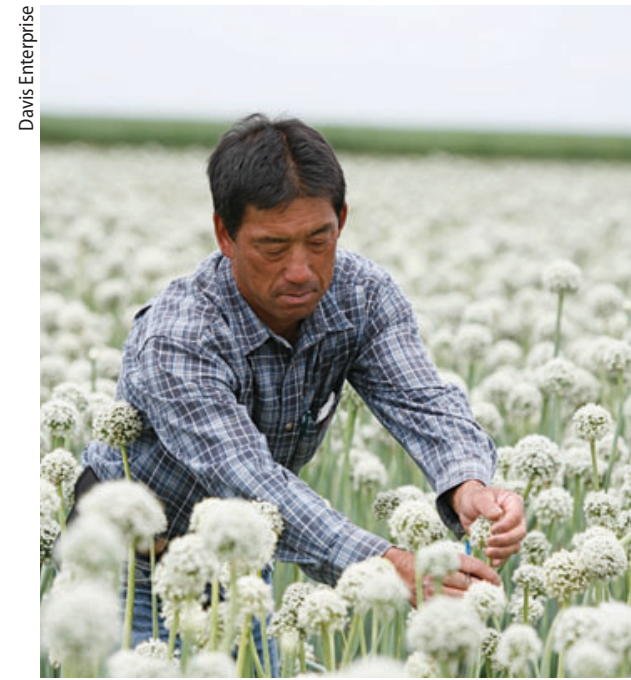

The researchers analyzed the relationships between field size, number of insecticides applied and honey bee visits. They also monitored seed yields and mapped nearby floral resources. Above, Yolo County field assistant Mark Kochi examines onion umbels.

tank mixes, with all pesticides applied prebloom (per agricultural commissioner county pesticide use reports). The number of hives per acre ranged from four to 14, with the exception of one field that had resident hives at 42 per acre (local beekeepers, personal communication).

In order to assess which factors were most predictive of honey bee activity, we performed a best subset regression analysis in $\mathrm{R}$ (HH package). Honey bee activity was the response variable, and the predictor variables were sugar solids in male and female flowers, hives per acre, number of bloom-applied pesticides (only fungicides were used during bloom), total number of insecticides applied, total number of systemic or translaminar (moving into the plant) insecticides applied and total number of pesticides applied (insecticides and fungicides).

\section{Honey bee observations}

In our flower visit observations, we measured a large amount of variation in honey bee activity among fields. The variation was highly correlated with onion seed set, with higher honey bee visitation showing higher numbers of seeds per umbel. This explains $77 \%$ of the variation among sites (fig. 2). These data strongly indicate that lack of pollen transfer is causing poor seed set in some onion fields.
There was no interaction between field and distance from the honey bee hives on the abundance of honey bees observed on flowers (Kruskal-Wallis chi-squared $=$ $0.9214, \mathrm{df}=2, P=0.6308)$. There was also no difference in honey bee abundance on male and female flowers (Kruskal-Wallis chi-squared $=0.2596$, $\mathrm{df}=1, P=0.6104$ ).

The best subset models of honey bee activity included size of field (higher bee activity with smaller fields, $P=0.0011$ ); total number of insecticides applied (higher bee activity with fewer insecticides used, $P=0.0219$ ); hives per acre (higher bee activity with more hives, $P=0.0232$ ); and sugar solids of male flowers, $15 \%$ to $27 \%$ (less bee activity with higher sugar solids, $P=0.0360$; adjusted $\mathrm{R}^{2}=0.704, \mathrm{~F}_{5,6}=6.232$, $P=0.0228$ ).

Univariate analyses of each of these factors showed that on their own, field size $\left(\mathrm{R}^{2}=0.36, \mathrm{~F}_{1,11}=6.15, P=0.0306\right)$ and number of insecticides applied $\left(R^{2}=0.24\right.$, $\mathrm{F}_{1,11}=3.14, P=0.0923$ ) were the strongest predictors of honey bee activity (fig. 3). This is consistent with a significant correlation found between increased insecticide use and decreased onion seed yields between 2003 and 2008 in Colusa County $\left(\mathrm{R}^{2}=0.87, \mathrm{~F}_{1,4}=25.77, \mathrm{P}=0.007\right)$ (fig. 4).

Although wild bees, flies and wasps are important pollinators of onions for seed, few were observed on the onion flowers in our study (less than $15 \%$ of the total number of pollinators), so no relationship was found between wild pollinator visits and seed set. Percentages of sugar solids were generally lower in our study than those reported in the literature

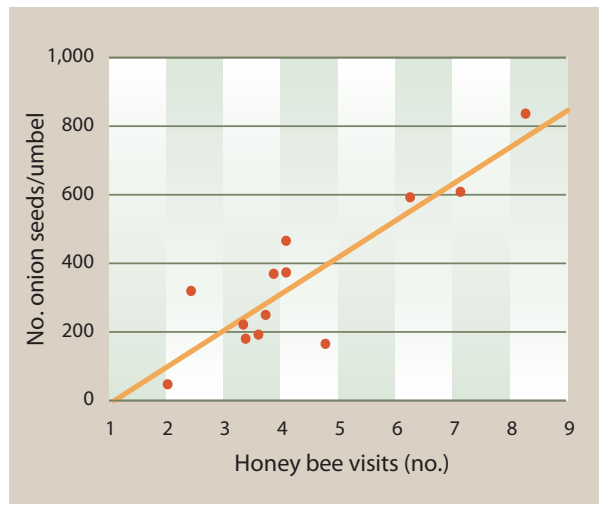

Fig. 2. Number of onion seeds per umbel per field versus number of honey bee umbel (flower) visits per 5-minute observation, Yolo and Sacramento counties, 2009.
(Gary et al. 1977; Hagler et al. 1990), possibly due to dilution of the nectar from condensation inside the bags. We did not analyze landscape data, because we did not find any significant vegetation in bloom within a mile of the flowering onion fields, except for the occasional alfalfa field that was late in a cutting cycle.

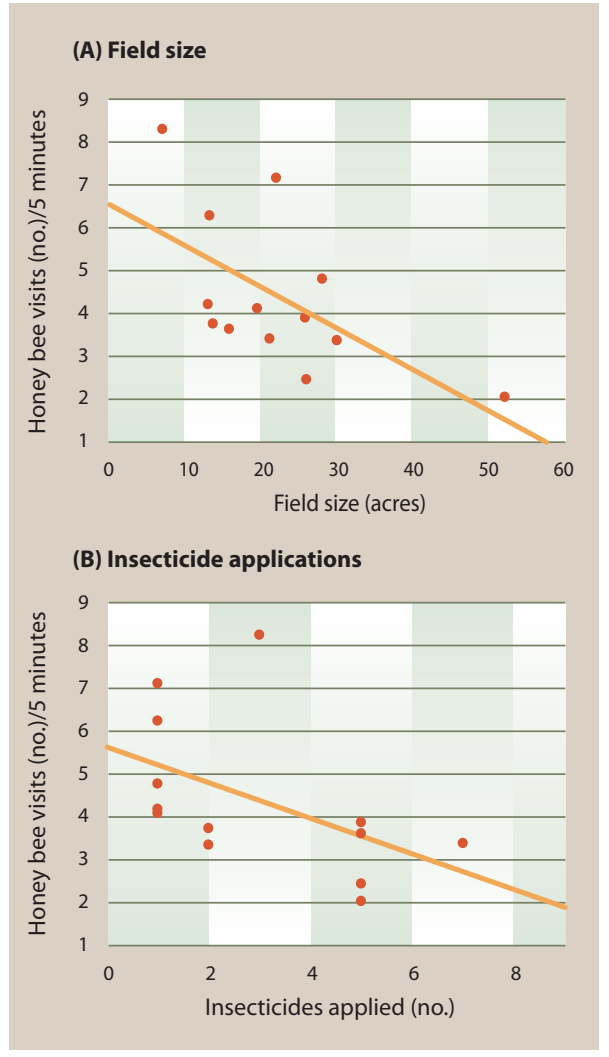

Fig. 3. Number of honey bee umbel (flower) visits per 5-minute observation versus (A) field size and (B) number of insecticides applied per field, Yolo and Sacramento counties, 2009.

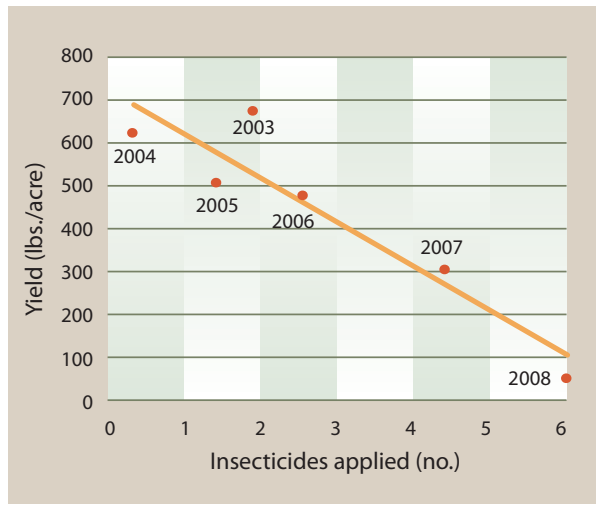

Fig. 4. Onion seed yields (pounds/acre) versus number of insecticides applied per field, Colusa County, 2003-2008. Source: Colusa County agricultural commissioner crop reports. 


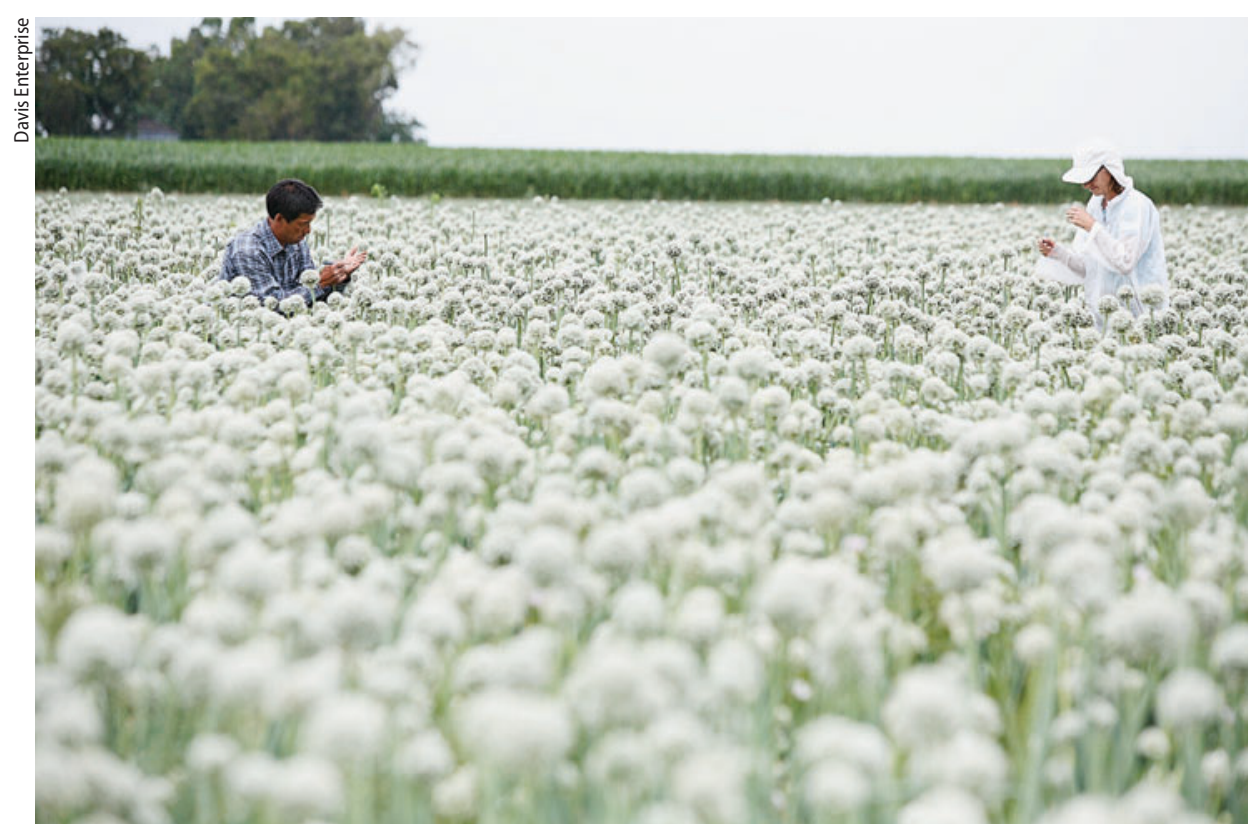

This study found that the number of insecticides applied and field size were the strongest predictors of honey bee activity and onion seed yields.

\section{Honey bee activity in onions}

Onion flowers are well known to be unfavorable to honey bees. Their unattractiveness may lie in the high level of potassium in onion nectar and limited nectar rewards (Silva and Dean 2000; Waller et al. 1972). Onion floral resources can vary by genotype, with some onion varieties being more attractive to honey bees than others (in part due to a higher sucrose content), as well as by environmental factors, including field and weather conditions (Carlson 1974; Hagler et al. 1990; Nye et al. 1971). For example, under higher temperatures, as onion nectar increases in viscosity it becomes less preferred by honey bees (Voss et al. 1999).

In our studies, fields with the same female or male cultivar did not cluster together in their level of honey bee activity, but with limited varietal replication it was not possible to draw conclusions about the impact of cultivar on honey bee activity.
We did not see any significant differences in honey bee activity on male versus female flowers to explain differences in umbel seed set between fields. Since the introduction of hybrid onion cultivars, the female lines may be less attractive to foraging honey bees (no pollen available) than the adjacent male fertile lines, possibly reducing pollination (Parker 1982). However, individual honey bees have been shown to move freely between hybrid onion male and female lines with

Competing, more-favorable floral resources in the landscape surrounding onion fields may draw honey bees away from onion seed crops, affecting pollination. As a result, the seed industry is careful to isolate fields so that competing flower resources do not occur at the same time within a mile of blooming onion fields. This field isolation was well observed in our study; the only competing resource that we occasionally observed good pollination (Gary et al. 1977). was alfalfa in bloom, and the fields were subsequently harvested as soon as growers were notified of the problem.

\section{Caution over insecticides}

The negative correlation that we found between honey bee activity and number of insecticides applied per field site (including tank mixes with more than one insecticide) (fig. 3B) suggests that insecticide use to control onion thrips may be affecting crop pollination and seed set, perhaps by killing or repelling honey bees. This would help explain the significant yield declines in Colusa County during the past 5 years, which occurred concurrently with an increase in insecticide use. However, to confirm a causal relationship, more information is needed on the specific effects of different classes and rates of insecticides on honey bee activity. In addition, cultivar choice can play a role in honey bee activity and needs to be further investigated with respect to pesticide use and bee activity.

Our study suggests that growers should exercise caution when using insecticides, applying them only when needed as opposed to preemptively, to better protect both wild and honey bee pollinators. Also, the negative correlation between field size and honey bee activity suggests that spreading honey bee colonies around onion fields rather than grouping them may increase honey bee activity and pollination in larger fields.

R.F. Long is Farm Advisor, UC Cooperative Extension, Yolo County; and L. Morandin is Postdoctoral Fellow, Department of Environmental Science, Policy and Management, UC Berkeley. We thank local bee keepers, the onion seed production industry and growers for their help with this project.

\section{References}

Carlson CE. 1974. Onion varieties, honey bee visitations, and seed yield. Cal Ag 28(9):16-8.

Gary NE, Witherell PC, Lorenzen K, Marston JM. 1977. Area fidelity and intra-field distribution of honey bees during the pollination of onions. Env Entomol 6(2):303-10. Gent DH, Schwartz HR, Khosla R. 2004. Distribution and incidence of IYSV in Colorado and its relation to onion plant population and yield. Plant Dis 88:446-52.
Hagler JR, Cohen AC, Loper GM. 1990. Production and composition of onion nectar and honey bee (Hymenoptera: Apidae) foraging activity in Arizona. Env Entomol 19(2):327-31

Nye WP, Waller GD, Waters ND. 1971. Factors affecting pollination of onions in Idaho during 1969. J Am Soc Hort Sci 96:330-2.

Parker FD. 1982. Efficiency of bees in pollinating onion flowers. J Kansas Entomol Soc 55(1):171-6.
Silva EM, Dean BB. 2000. Effect of nectar composition and nectar concentration on honey bee (Hymenoptera: Apidae) visitations to hybrid onion flowers. J Econ Entomol 93(4):1216-21.

Voss RE, Murray M, Bradford K, et al. 1999. Onion Seed Production in California. UC ANR Pub 8008. Oakland, CA. $10 \mathrm{p}$.

Waller GD, Carpenter EW, Ziehl OA. 1972. Potassium in onion nectar and its probable effect on attractiveness of onion flowers to honey bees. J Amer Soc Hort Sci 97:535-9. 